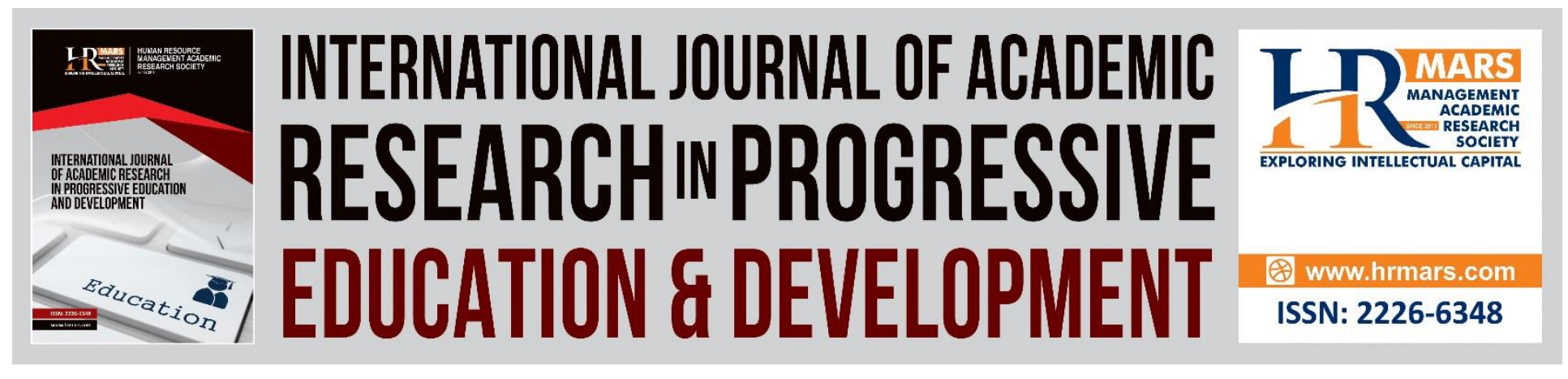

\title{
The Effectiveness of Storytelling Method in Experiential Learning Model to Improve the Senior High School Students' Ability in Deducting Negative Stereotype
}

Yohanes Yupilustanaji Apgrianto, Marthen Pali, Dany M. Handarini, Muslihati

To Link this Article: http://dx.doi.org/10.6007/IJARPED/v7-i2/4183

DOI: $10.6007 /$ IJARPED/v7-i2/4183

Received: 26 Nov 2018, Revised: 18 April 2018, Accepted: 03 June 2018

Published Online: 20 June 2018

In-Text Citation: (Apgrianto, Pali, Handarini, \& Muslihati, 2018)

To Cite this Article: Apgrianto, Y. Y., Pali, M., Handarini, D. M., \& Muslihati. (2018). The Effectiveness of Storytelling Method in Experiential Learning Model to Improve the Senior High School Students' Ability in Deducting Negative Stereotype. International Journal of Academic Research in Progressive Education and Development, 7(2), 86-95.

Copyright: (C) 2018 The Author(s)

Published by Human Resource Management Academic Research Society (www.hrmars.com)

This article is published under the Creative Commons Attribution (CC BY 4.0) license. Anyone may reproduce, distribute, translate and create derivative works of this article (for both commercial and non-commercial purposes), subject to full attribution to the original publication and authors. The full terms of this license may be seen

at: $\underline{\text { http://creativecommons.org/licences/by/4.0/legalcode }}$

Vol. 7, No. 2, April 2018, Pg. 86 - 95

http://hrmars.com/index.php/pages/detail/IJARPED

JOURNAL HOMEPAGE

Full Terms \& Conditions of access and use can be found at http://hrmars.com/index.php/pages/detail/publication-ethics 


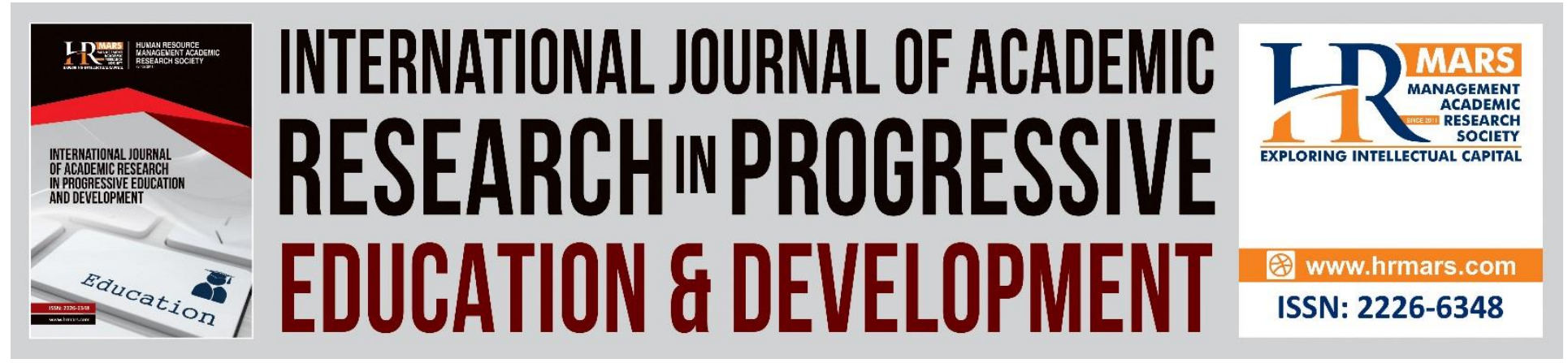

\title{
The Effectiveness of Storytelling Method in Experiential Learning Model to Improve the Senior High School Students' Ability in Deducting Negative Stereotype
}

\author{
Yohanes Yupilustanaji Apgrianto ${ }^{1,2}$, Marthen Pali ${ }^{1}$, Dany M. \\ Handarini ${ }^{1}$, Muslihati ${ }^{1}$ \\ ${ }^{1}$ Graduate Program of Guidance and Counseling, Universitas Negeri Malang, Indonesia \\ ${ }^{2}$ Corresponding Author - Email: yupilustanaji82@gmail.com
}

\begin{abstract}
The history of Indonesia was prove that a conflict among various group of ethnic group, religious and racial group were often coloring this nation's life. This is shows that diversity and differentiation is still considered as a threaten situation. The conflicts mentioned is actually based on the negative stereotype that is expanding in each individual and civilization group. The research is done to verify the effectiveness of storytelling method in experiential learning model to improve the senior high school students' ability in deducting negative stereotype. The one group pretest-posttest design was used as a research design. The asymp.-sig. (2-tailed) of the Wilcoxon-Signed-Ranks-Test for after-before treatment (or Z score) is less than 0.05 . It shows that storytelling method in experiential learning model is effective to improve the senior high school students' ability in deducting negative stereotype. The further researchers are suggested to use a control group.

Keywords: Storytelling, Experiential Learning, Negative Stereotype, Ability In Deducting Negative Stereotype

Introduction

Stereotype is a form of thought that categorize someone else in a group that has the properties, types, attributes, or specific labels (Moskowitz, 2012; Flanagan \& Green, 2011; Zelts et al., 2014; Zikarge, 2013). Indeed, stereotype is neutral because it is a part of human cognitive natural function (Zielts, 2014), even some of the studies, showed that stereotype has a positive effect if it is used accurately (Cox \& Devine, 2015; Atkinso et al., 2003), stereotype is can be negative because the process of categorizing above used a negative perspective (Hogan, 2013).
\end{abstract}


Vol. 7, No. 2, April 2018, E-ISSN: 2226-6348 @ 2018 HRMARS

This negative stereotype is triger the existence of bias and realizes the preconceptions, then surface the misunderstanding and potentially surfaces the conflict, among individual or groups (Zikarge, 2013). In other words, negative stereotype is the most determine factor in making the acrimonious relation and a graceful situation (Zelts et al., 2015; Zikarge, 2013).

Hogan (2013) stated that the ability in deducting the negative stereotype, including the four multicultural skills which is need to be owned by individual in order to have a harmony live in an environment which is full of cultural diversity. Hogan (2013) also emphasize that the ability in deducting the negative stereotype is the initial formation foundation of multicultural skills. An individual who has the ability in deducting the negative stereotype will endeavor to open and attempt to construct the trust when interact with another which has a different cultural background (Mattews et al., 2011; Hogan, 2013; Zelts et al., 2015). Hwang et al. (2010) added that the ability mentioned will make an individual able to make a decision independently (based on self-manufacturing) without fully affected by a negative stereotype. This is an individual who has sincerity in behaving flexible or supple toward another, accepting the differentiation and trying to build harmoniousness with another (Degni et al., 2012; Hogan, 2013; Zikarge, 2013).

On the other hand, consciously or unconsciously when an individual is making an interaction with another, they will be very easy influenced by the negative stereotype if they do not have the capability mentioned. These things are making a relation among people filled of disagreement because misunderstanding caused by the negative stereotype (Tryten et al., 2012; Angermeyer \& Matschinger, 2005; Zikarge, 2013). The research findings also emphasizes that individual who has not able in deducting the negative stereotype will keep a distance with others (Angermeyer \& Matchinger, 2015; Zelts et al., 2015), despise other indivduals (Buken, 2003; Pavlova et al., 201; Pennington et al., 2015), easy to prosecute or judge with no basis (Cox, 2015; Aronson et al., 2013; Tryten et al., 2012), tend to trigger personal anger or any other different group (Zelts, 2015) and tend to unable to give a trust to an individual of different cultural background (Zelts, 2015). From the fact, it is definitely necessary for an individual that cannot easily be controlled and influences by any negative stereotype. It is greatly important for an individual to have an ability in deducting negative stereotype particularly for individuals living in a situation with various cultural backgrounds.

Indonesia is a compound nation in the matter of culture, religion, ethnic group and languages. Statistic data show that Indonesia is one of the most compound nation the world in the matter of cultural diversity. But the history of this nation proves that various conflict among the ethnic groups, religion and racial group is often coloring the daily live of this nation. This is shows that variation and differentiation is still viewed a threaten situation for some societies. In Java context, Indonesia, disharmony relation among individual with cultural differentiation is not only happening in context of social life, but also the rampant lately, disharmony endless unrest also often occur in the educational environment, such as the riots between Papua's students and Javanese Students in Yogyakarta (July, 2016), thousands of NTT students out of Yogyakarta city because they were feuded with students from other regions (March, 2013), riot between Maluku students resist the Sumba students at Malang (March, 2016), brawl between NTT Students and other students at Malang region (March, 2016) and other the same cases. In the case of exemplified mentioned, negative stereotype is the source of the cause which is very crucial, because of hatred against a group of students of the Maluku, Sumba, East Nusa Tenggara, Java 
Vol. 7, No. 2, April 2018, E-ISSN: 2226-6348 @ 2018 HRMARS

triggered also by a form of negative stereotype that pinned people with cultural background of Maluku, Sumba, East Nusa Tenggara, and Java.

Indeed the founding fathers of Indonesia have set a watchword of the nation which could bring together the differences between cultures. The watchword is Bhineka Tunggal Ika which means different but still one. The watchword taken from Sutasoma book by Empu Prapanca which reveals how beautiful and meaninglessness the unity, peace and harmony of the various elements of diversity. Since being in elementary school even in the kindergarten, every Indonesian student gave understanding to perceive the meaning of watchword Bhineka Tunggal I $k a$, for the sake of state and nation in harmony and peace, although consisted of various cultural backgrounds. Nevertheless, in the realm of practical field, it turns out that these ideals are still far from reality. The human factor (teacher and educator) which is less prepared, then the curriculum is too fast to change, make the values done less well. It is definitely necessary for Indonesian to have open personal to any differences of individuals, they are open to any inter cultural differences and try to cooperate in an effective and efficient manner with others from different cultures. A basic question from the above explanation is what is the educational world strategy to free Indonesian young generations from any interactions that are influenced by negative stereotype?

The problems related to the negative stereotype because closely related to the factors of the non-cognitive students so guidance and counseling service at schools take a responsible for the full response to the problem is to affirm the program of guidance and counseling which is aimed to improve Indonesian students' ability in deducting negative stereotypes. This research is endeavor to improve guidance and counseling service which is attempt to improve senior high school students ability in deducting negative stereotypes. As for the process of improving the ability to reduce negative stereotypes this study using theory Identity change steps by Hogan (2013), which is aim to make an individual able to reduce the negative stereotype in themselves through five steps, they are, (1) Conformity, (2) Resistance, (3) Redefinition, (4) New Identity and (5) Diversity Competence. And then, the factors or the reason of using senior high school as the research object in this research because they are classified as adolescence and it is a step where they are experiencing a crucial individual growth and they start to construct their identity, such as arranging the foundation values of live independently (Cross \& Fletcher, 2011). In this step, individual realize the harder moral conflict between the ideal and real, including the truth and stereotypes (Zelts, 2015). In Indonesia context, Hasan and Suwarni (2012) states in their research that is sentiment between groups (including a sentiment between racial or ethnic group) in Indonesia has been arising and rapidly growing in adolescence to adulthood.

Then, experiential learning model is chosen to be a model to improve students ability in deducting negative stereotypes because, first, results of the latest research proved the effectiveness of experiential learning model in improving cultural awareness and so, improve the ability in deducting negative stereotypes (Flanagan, 2009; Katzke, 2013; Bohman et al., 2014; Wilk, 2012; Pirkey et al., 2012, Carpenter \& Garcia, 2012, Michajlyszyn et al., 2012, Cisneros et al., 2013, Mc Dowell et al., 2012). Second, this strategy is effective to improve the ability in deducting negative stereotype with its characteristics, they are, (1) tend not to be neutral and rule out objectivity, (2) constituted by beliefs, thoughts or ideology that already perceived before and (3) consciously or unconsciously, influence a certain view toward a subject, due to experiential learning model, someone will be able to criticize the view subjectively and then 
Vol. 7, No. 2, April 2018, E-ISSN: 2226-6348 @ 2018 HRMARS

criticize the ideology which has been existing before. Third, based on a research conducted by Zikarge (2013) states that stereotypes is arise because the limitation of information, the limitation of interaction and the limitation of experience, so experiential learning model transform the experience become a very suitable knowledge to skim over the growth of negative stereotypes (Kolb, 1984).

Further, based on the explanation in The Handbook of Experiential Learning (Silberman, ed. 2007) which summarize the results of implementing experiential learning model stated that experiential learning model is open to the methods. Therefore, in this research, storytelling method is chosen as a method in presenting the next real experience which will be reflected and transformed to be knowledge. The reason for choosing this method because of listening to storytelling is effective to criticize and change the views and perspectives or to renew them (Gargiuolo, 2007; Walton, 201; Pavlova, 2014). In line with these things, in Indonesia context, research by Hasan \& Suwarni (2012) emphasize that stories, especially traditional stories can be used in understanding and comprehending other cultures, so it could reduce the negative stereotypes. Thus, through storytelling method, individual was brought into the world of abstraction then attract them to meditate, reflect on, to criticize and to revise their own experience related to the world displayed in the storytelling.

Hence, the aim of this research is to verify the effectiveness of storytelling method in experiential learning model in improving senior high school students' ability in deducting the negative stereotypes. Then, for counselors, it is expected to provide more ability to understand and apply any works to improve the ability in deducting the negative stereotype for Senior High School students.

\section{Method}

The research was done at SMAK Mater Dei at Probolinggo, Indonesia with the 10th and 11th grades (210 students) as the population of the research. The subject of this research was 7 students chosen by using random sampling techniques. Target of the research was students with low ability in deducting the negative stereotype, after measured by using the Negative Stereotype Reduction Skill Scale.

The variable ability in deducting the negative stereotype consisted of 5 parts, they are conformity, resistance, redefinition, new identity and diversity competence, so, the instrument of the Negative Stereotype Reduction Skill Scale consisted of those 5 parts. The readability of the draft instrument has been reviewed, and then tested to 80 respondents that is the students of SMA Cor Jesu at Malang, Indonesia. Test construct validity of the instrument was performed with exploratory factor analysis, then only the valid particle that have a loading factor equal or more than 0.5 , and grouping in the same certain component. After the particles were compiled, obtained the result: 104 items. Then level of the reliability tested by Alpha Cronbach and got the score: 0.919. Result of the measurement from the scale mentioned followed up with the interview and intake review as the strengthener that the students chosen based on the research target.

Group guidance with storytelling method in experiential learning model is done by experiment with one group pretest posttest design with the used of Negative Stereotype Reduction Skill Scale as the instrument. This research used technical analysis of The Wilcoxon 
INTERNATIONAL JOURNAL OF ACADEMIC RESEARCH IN PROGRESSIVE EDUCATION AND DEVELOPMENT

Vol. 7, No. 2, April 2018, E-ISSN: 2226-6348 @ 2018 HRMARS

Matched pairs Signed-ranks Test, which is used to analyze the improvement score in deducting the negative stereotype in pretest and posttest intervention.

\section{Results}

Before explaining the measurement result, there is hypothesis of this research, as follow: $\mathrm{H}_{0}$ : storytelling method in experiential learning method is not effective in improving senior high school student ability in deducting negative stereotypes.

The criteria for rejecting $\mathrm{H}_{0}$ is that the asymp.-sig. (2-tailed) of the Wilcoxon-SignedRanks-Test for after-before treatment (or Z score) is less than 0.05 . The $Z$ score is -2.366 , and the asymp.-sig. is 0.018 . Because the asymp.-sig. is less than $0.05, \mathrm{H}_{0}$ is rejected. It means that storytelling method in experiential learning model is effective to improve the senior high school students' ability in deducting negative stereotype.

The effectiveness mentioned proved by the score improvement students' ability as the research subject in deducting the negative stereotypes which was measured with The Negative Stereotype Reduction Skill Scale. On the pretest, the students' ability as the research subject in deducting the negative stereotypes is on the low level, and being on the average level in posttest.

\section{Discussion}

From the result of measurements that have been done, added by the analysis above, it can be concluded that the improvement of research subject ability in deducting the negative stereotypes is caused by the intervention given by using stereotype method in experiential learning model. Start from the first step of experiential learning model, that is, Concrete Experience (CE). This step presenting the experience related to the negative stereotype delivered by using storytelling method (Gargiuolo, 2007). Deliver the story by using storytelling method which is listened and understood well, will trigger a view transformation from the research subject. It is convinced the discovering of the same story or experience that is experienced by the research subject. In this step, the research subjects aware of the existence of negative stereotypes in their experience and resulting the negative impact. Besides, this step cause a change in the research subject who were not aware of the existence of negative stereotypes and becomes conscious of its existence and its negative impact in their life.

Then, second step on experiential learning is Reflective Observation (RO). In this step, the research subject is guided to make a self-reflection by answering to the reflexive questions arranged based on GURU (Ground, Understand, Revise and Use) reflection model (Remer, 2007). And then, experience contains negative stereotypes that has been realized in the previous steps will be processed and reflected personally in this RO step. Improvement on the ability of deducting the negative stereotype is happening in this step when the research subject understands well the negative stereotypes implied in their experience (question about Ground and Understand). In advanced, improvement on the ability is happening when the research subjects reflect on and consider about the thing they could correct (question about Revise). The process continues by attempting individually to abbreviate a desire and commitment if the same experience is happening in the future with the aim to decrease the existence of negative stereotypes and its impact (question about Use).

Hereinafter, a transformation experienced by the research subjects when they are in the third step of experiential learning is, Abstract Conceptualization (AC). In this step, the research 
Vol. 7, No. 2, April 2018, E-ISSN: 2226-6348 @ 2018 HRMARS

subjects along with the group member guided by the counselor formulate the concept, understanding and the new meaning when they faced a negative stereotype experience. By formulating the accurate concept jointly, research subject is persuaded individually or jointly to reduce negative stereotypes and its impacts. Therefore, after all the steps, the research subjects are aware and understood the negative stereotype that they have and making a commitment individually to correct them in one reflective process, so in this process, the research subject is persuaded jointly in a group guided by a counselor to formulate the concept, understanding and a new perspective towards an experience consist of negative stereotypes. Because the new concept is formulated jointly, negative stereotypes is scraped off and wiped out.

After AC step, a transformation which is happening in the research subject when they are in the last step of the four steps in experiential learning model is Active Experimentation (AE) step. Here, the research subject is guided to implement the concept of understanding and a new perspective which have been formulated before in the previous step, in the form of behavior and daily attitude. In this step, the research subject concretely attempt to reduce negative stereotype not only in cognitive level or affective, but evidently go in psychomotor area because directly related with daily attitude.

From the explanation above, it can be concluded that the first factor influenced towards the improvement of the ability in deducting the negative stereotypes is mind transpiration of the research subject towards an experience and transformation mentioned towards experience and transform the experience to be a knowledge which will be able to improve the ability in deducting the negative stereotypes. The explanation related to the suitability between the result of this research is the improvement on the students of senior highs school ability in deducting negative stereotypes with the theory Identity Change Stages (Hogan, 2013) which is consist of 5 steps, namely (1) Conformity, (2) Resistance, (3) Redefinition, (4) New Identity, and (5) Diversity Competence. Started from the first step, that is Conformity, a step when a person is not realize the hefty influence of negative stereotype, so they were controlled by the negative stereotypes easily in their daily life. It can be showed from the expression written on their reflective writing as follows, before implementing the intervention the research subject were not aware that they were often giving a negative stereotypes easily. They were not aware of feeling anxious when they meet people that they have not known before and always put a negative stereotypes on them. Besides, they were not aware if negative stereotypes caused the appearance of feeling animosity, antagonism, cannot accept other people and stay away from other people.

Next step is Resistance. Here, the person was asking and resisting the existence of negative stereotypes. It can be showed in from the expression written by the research subjects as follows, that is research subject feel that they more critical to the emergence of the negative stereotypes in itself. It can be showed that they were trying to open themselves to see the possibilities and personal background which is affected the negative stereotypes and trying to correct them first before giving negative stereotypes and blame other people. During the intervention, the research subject also aware of the need for questioning the existence of negative stereotypes in them, because negative stereotypes always different with reality. Therefore, research subject need to ask to people who affected the negative stereotypes in order to consider them objectivity.

The third steps is Redefinition, is a step when individual is starting to redefine the negative stereotypes in it. It can be showed from the expression of the research subjects as follows, that 
Vol. 7, No. 2, April 2018, E-ISSN: 2226-6348 @ 2018 HRMARS

the research subjects aware on the necessity of having a positive thinking in order to correct the negative stereotypes. Besides, they were aware that negative stereotypes is need to be processed and change with the new perspective, especially open minded, accepting and respect other people, that is New Identity and Diversity Competence, seen from the analysis on their reflective written, they have not experienced the real one. Because of they just attaint the Redefinition step, so their posttest is in average level and they have not get a high category in the ability of deducting the negative stereotypes.

\section{Conclusion and Suggestion}

Based on the statistic analysis using The Wilcoxon Matched-pairs Signed-rank Test, it is known that the storytelling method in experiential learning model is effective to improve the ability in deducting the negative stereotype by senior high school students. This effectiveness is proven by improved score of the ability in deducting the negative stereotype by the subjects that are measured by Negative Stereotype Reduction Skill Scale. At the pretest, subjects' ability in deducting the negative stereotype was in low category, but in posttest, it was in medium high category. Suggestion for further researcher is to follow up this research by using a control group, hence storytelling method in experiential model can be more tested. Besides, the further researcher can test the implementation of storytelling method in experiential learning model in order to improve other life skills.

\section{References}

Angermeyer, M.C \& Matschinger, H. (2005). Labeling-stereotype-discrimination; An investigation of the stigma process, Soc Psychiatry Epidemic, 40, 391-395

Aronson, J., Burgess, D., Phelan, S. M., Juarez, L. (2013). Unhealthy Interaction The Role of Stereotype Threat in Health Disparities, American Journal of Public Health, 103 (1), 50-55

Atkinso, C., Kuhne, T., Sellers, B. (2003). Systematic stereotype usage, Soft Syst Model, 2, 153-163

Bohman, D.M \& Borglin, G. (2014). Student exchange for nursing student: Does it raise cultural awareness? A descriptive, qualitative study, Nurse Education in Practice, 14, 259-264

Buken, G (2002), Construction of the Mythic Indian in Mainstream Media and the Demystification of the Stereotype by American Indian Artist, American Studies International, 40 (3), 46-56

Carpenter, L.J., Garcia, A.A. (2012). Assessing Outcomes of a Study Abroad Course, Nursing Education Perspectives, 33 (2), 85-89

Cisneros, R.M., Jawaid, S.P., Kendall, D.A., Mc Pherson, C.E., Mu, K., Wetson, G.S \& Roberts, K.B. (2013). International Practice Experiences in Pharmacy Education, American Journal of Pharmaceutical Education, 77 (9), 1-6

Cox, W. L \& Devine, P.G. (2015). Stereotypes Posses Heterogeneous Directionality: A Theoretical and Empirical Exploration of Stereotype Structure and Content, PLOS ONE, 10 (3), 1-27

Cross, J. R \& Fletcher, K.L. (2011). Association of Parental and Peer Characteristics with Adolescents' Social Dominance Orientation, J Youth Adolescence, 40, 694-706

Degni, F., Suominen, S., Essen, B., Ansari, W.E \& Vehvilainen-Julkunen, K. (2012). Communication and Cultural Issues in Providing Reproductive Health Care to Immigrant Women: Health Care Providers' Experiences in Meeting Somali Women Living in Finland, J Immigrant Minority Health , 14, 330-343 
INTERNATIONAL JOURNAL OF ACADEMIC RESEARCH IN PROGRESSIVE EDUCATION AND DEVELOPMENT

Vol. 7, No. 2, April 2018, E-ISSN: 2226-6348 @ 2018 HRMARS

Flanagan, C.A., Syvertsen, A. K., Gill, S., Gallay, L.S., Cumsille, P. (2009). Ethnic Awareness, Prejudice and Civic Commitments in Four Ethnic Groups of American Adolescents, $J$ Youth Adolescence, 38, 500-518

Flanagan, J \& Green, R. (2011). Stereotype Threat In Manual Labor Settings For Hispanic And Caucasian Participants, Journal of Organizational Culture, Communications and Conflict, $15(2), 111-132$

Gargiuolo, T. (2007). Storytelling (M. Silberman, Ed.). San Fransisco: John Wiley \& Sons, Inc

Hasan, A.B.P \& Suwarni, E. (2012). Policies and Practices for Promoting Multicultural Awareness of Indigenous Early Childhood Education in Indonesia, International Journal of Child Care and Education Policy, 6 (1), 63-94

Hogan, M. (2013). Four Skills: Cultural Of Diversity Competence, California: Brooks/Cole Cengage Learning

Hwang, J.P., Roundtree, A.K., Engebretson, J.C \& Suarez-Almazor, M.E. (2010). Medical Care of Hepatitis B among Asian American Populations: Perspectives from Three Provider Groups, J Gen Intern Med 25(3), 220-227

Kolb, D. (1984). Experiential Learning: Experience as a source of learning and development, Englewood Cliffs NJ: Prentice Hall

Kratzke, C \& Bertolo, M. (2013). Enhancing Students' Cultural Competence Using Cross-cultural Experiential Learning, Journal of Cultural Diversity, 20(3), 107-110

Mathews, J.L., Parkhill, A.L., Schlehofer, D. A., Starr, M.J \& Barnett, S. (2011). Role-Reversal Exercise with Deaf Strong Hospital to Teach Communication Competency and Cultural Awareness, American Journal of Pharmaceutical Education, 75 (3), 1-10

Mc Dowell, T., Goessling, K \& Melendez, T. (2012). Transformative Learning Through International Immersion: Building Multicultural Competence In Family Therapy and Counseling, Journal of Marital and Family Therapy, 38 (2), 365-379

Michajlyszyn, C.M., Thompson, K.A., Stiller, C.H \& Doherty, D.J. (2012). Guest Lecturing in South Korea: Informing Cross-Cultural Educators of Physical Therapy, Journal of Physical Therapy Education, 26 (1), 40-49

Moskowitz, G.B., Stone, J., Childs, A. (2012). Implicit Streotyping and Medical Decisions: Unconscious Stereotype Activation in Practitioners' Thought About African Americans, American Journal of Public Health, 102 (5), 996-1001

Pavlova, M.A., Weber, S., Simoes, E., Sokolov, A.N. (2014). Gender Stereotype Susceptibility, PLOS ONE, 9 (12), 1-13

Pennington, C.R., Heim, D., Levy, A.R., Larkin, D.T (2016). Twenty Years of Stereotype Threat Research: A Review of Psychological Mediators, PLOS ONE, 11 (1), 1-25

Pirkey, J.M., Levey, J.A., Newberry, S.M., Guthman, P.L \& Hansen, J.M. (2012). Videoconferencing Expands Nursing Students' Cultural Realm, Journal of Nursing Education, 51 (10), 586-590

Remer, B. 2007. Reflective Practice; Learning from Real-World Experience (M. Silberman, Ed.). San Fransisco: John Wiley \& Sons, Inc

Silberman, M. (Ed.) 2007. The Handbook Of Experiential Learning. San Fransisco: John Wiley \& Sons, Inc

Trytten, D.A.,Lowe, A.W.,Walden, S.E. (2012). "Asians are Good at Math. What an Awful Stereotype": The Model Minority Stereotype's Impact on Asian American Engineering Students, Journal of Engineering Education, 101 (3), 439-468 
Vol. 7, No. 2, April 2018, E-ISSN: 2226-6348 @ 2018 HRMARS

Walton, J. (2011). Can a One-Hour Presentation Make An Impact on Cultural Awareness?, Nephtology Noursing Journal, 38 (1), 21-30

Wilk, N.C. (2012). Nursing students'cultural immersion in Kenya: A case for a clinical capstone site, Journal of Nursing Education and Practice, 3 (5), 39-44

Zelst, C., Nierop, M., Dam, D., Velthuis, A.A., Delespaul, P. (2015). Association between Stereotypes Awareness, Childhood Trauma and Psychopathology: A Study in People with Psychosis, Their Siblings and Controls, PLOS ONE, 10(2), 1-15

Zelst, C.,Nierop, M., Oorschot, M., Germeys, I., Os, J.,Delespaul, P. (2014). Stereotype Awareness, Self Esteem and Psychopatology in People with Psychosis, PLOS ONE, 9 (2), 1-6

Zikargae, M. H. (2013). The Impacts of Ethnocentrism and Stereotype on Inter-Cultural Relations of Ethiopian Higher Education Students, Online Journal of Communication and Media Technologies, 3(4), 126-148. 